\title{
DESIGN DE MÓVEIS POPULARES: incongruências entre oferta e demanda
}

\author{
Priscilla Ramalho Lepre \\ Universidade Federal de Alagoas \\ cillaramalho@yahoo.com.br
}

\begin{abstract}
Resumo: Este artigo apresenta os resultados parciais de pesquisa realizada para compor dissertação entregue para obtenção do Título de Mestre em Design. Trata das incongruências entre os móveis populares ofertados pelo mercado brasileiro e as necessidades da população de baixa renda, particularmente as que dizem respeito às demandas das atividades de montagens e desmontagens destes produtos durante seu ciclo de vida. Apresenta, também, exemplos de danos causados por falhas durante estes processos e propõe a inserção de mecanismos à prova de erros, denominados Poka-Yoke, como solução para reduzi-los, como forma de garantir a completude da vida útil deste produtos e, desta forma, contribuir para a Sustentabilidade nos três pilares - ambiental, econômico e social.
\end{abstract}

Palavras-chave: design, sustentabilidade, mobiliário polupar, interesse social, poka-yoke.

\section{INTRODUÇÃO}

O mercado brasileiro de móveis populares está em franca ascensão. Segundo pesquisa realizada pela FEA/USP - Faculdade de Economia, Administração e Contabilidade, as empresas que investem em produtos para as classes $C, D$ e $E$ apresentaram o melhor desempenho financeiro do setor entre 2002 e 2012 (BERNARDES,2014). Os principais responsáveis por este aumento são: as novas políticas públicas de distribuição de renda e a oferta de crédito para compras no varejo por lojas especiaizadas. Isto reflete a compreensão macro da importância deste novo mercado na economia brasileira.

Buscando conhecer estes consumidores, nos últimos anos, pesquisas relacionadas tem apontado divergência entre peculiaridades das moradias de interesse social, o ciclo de vida de seus habitantes e os produtos à eles destinados. A dimensão do mobiliário, materiais, acabamentos, inflexibilidade e inadaptabilidade, figuram entre as mais frequentes. (LEPRE; SOARES E NASCIMENTO, 2008). Outro aspecto importante desconsiderado no design de móveis populares é o processo de montagem e desmontagem destes produtos. Sua relevância deve-se principalmente a mobilidade desta população devido ao déficit habitacional brasileiro. Segundo o IPEA (2012), este atinge 73,6\% das famílias que recebem até 03 (três) salários mínimos mensais. 
O presente artigo, portanto, trata das incongruências entre os produtos ofertados pelo mercado de móveis populares e as necessidades destes consumidores, principalmente no que tange ao processo montagem/desmontagem, trazendo os resultados de uma etapa da pesquisa realizada e concluída pelo Núcleo de Design e Sustentabilidade da Universidade Federal do Paraná - NDS/UFPR, denominada KITS Do-It-Yourself, com o objetivo de fomentar as mudanças no setor moveleiro necessárias para melhorar a sustentabilidade no âmbito ambiental, econômico e social.

\section{PROJETO KITS-DO-IT-YOURSELF - BREVE HISTÓRICO}

O Projeto "Kits faça-você-mesmo coordenados modularmente para cobertura e mobiliário-divisória de habitações de interesse social", aprovado na "Chamada Pública MCT/FINEP/FNDCT/CAIXA - HABITARE - 01/2006 e conduzido pelo Núcleo de Design e Sustentabilidade da Universidade Federal do Paraná, teve como objetivo principal a geração de metodologias para criação e desenvolvimento de "kits" para a habitação de interesse social, segundo os princípios da sustentabilidade.

O "kit" de mobiliário-divisória, cuja uma das etapas de pesquisa é apresentada neste artigo, teve como meta a concepção e desenvolvimento de um mobiliário (até a fase de protótipo funcional) coordenado modularmente, que integrasse, em um mesmo produto, a função de mobiliário e divisória entre ambientes. Este móvel deveria incorporar, na sua concepção, os princípios da sustentabilidade nas três dimensões, bem como os princípios da ergonomia e usabilidade do produto. Deveria, também, impreterivelmente, ser passível de ser transportado e montado pelo usuário final.

Com a finalidade de facilitar este processo, tornando mais seguro e evitando erros que poderiam provocar danos que levassem redução de sua vida útil e descarte prematuro, optou-se por incluir dispositivos à prova de erros humanos, chamados Poka-Yokes. Estes são mecanismos ou procedimentos utilizados para prevenir erros em produtos, sistemas ou processos, idealizados e desenvolvidos primeiramente pelo engenheiro Shigeo Shingo, a fim de proteger a produção industrial da Toyota, de erros banais que pudessem vir a se transformar em produtos defeituosos (TSOU \& CHEN, 2005).

Como suporte à esta pesquisa, realizou-se revisão de literatura na área de Design para Sustentabilidade, Engenharia da Produção, Ergonomia, Usabilidade e Erros Humanos, a partir da qual definiu-se o conjunto de Métodos de Pesquisa, que contou, dentre outros, com duas Mini-Surveys e um Estudo de Caso.

A primeira fase de coleta de dados, teve como objetivo verificar os produtos expostos para a venda e conhecer a dinâmica do uso nas casa de interesse social, delineando as lacunas entre ambos, principalmente relativas as atividades de montagem e demontagem, seu ciclo de vida e os impactos destes processos na durabilidade do mobiliaário popular. Os resultados desta fase são detalhados na sequência quanto a metodologia aplicada, instrumentos de coleta de dados, resultados e análises.

\subsection{Metodologia de pequisa}

Conforme apresentado anteriomente, este artigo recorta a primeira fase da coleta de dados para o Projeto Kits Do-It-Yourself, realizado pelo NDS/UFPR, na qual 
empregou-se a Survey como método principal, por responder questões do tipo "o que", "por que", "como" e "quanto" de evento contemporâneos sobre os quais não se controle (FREITAS ET AL, 2000).

Para traçar um panorama das relações entre o que é ofertado pelo mercado e as necessidades psicográficas das famílias de baixa renda, foram realizadas 02 (duas) Mini-Surveys, sendo a primeira em lojas de móveis populares e a segunda em habitações de interesse social. Entre as formas de condução de Surveys, propostas por Robson (2006), optou-se, pela entrevista face-à-face, pois a característica dos dados a serem coletados em ambas Mini-Surveys, prescinde da observação in loco dos produtos e seus contextos. Os instrumentos de pesquisa utilizados foram: questionários, entrevista semi-estruturada, observação direta com roteiro prédeterminado, apoiados por coleta de imagem e som. Para sua elaboração utilizou-se a base teória já nominada.

Os critérios de seleção das amostras e a condução de cada Mini-Survey são apresentados na sequência. Os resultados das coletas de dados das mini-surveys supracitadas são apresentados em separado. Contudo, de maneira a criar um panorama geral das relações entre a oferta e a realidade de uso do mobiliário popular, a análise dos dados será feita de forma conjunta e comparativamente.

\subsection{Mini-Survey em Loja de Móveis Populares (MS1) - protocolo de coleta de dados}

Conforme descrito, a primeira Mini-Survey visava traçar o perfil dos produtos ofertados pelo mercado. Conduzida em Loja de Móveis Populares, teve como amostra 05 (cinco) estabelecimentos de grande porte na cidade de Curitiba, selecionadas segundo os seguintes critérios: capacidade de oferta própria de crédito ao consumidor, público alvo e categoria de produtos. O público alvo deveria ser a população de baixa renda, caracterizada pelo rendimento mensal de até 03(três) salários mínimos (IPEA, 2013). O produtos ofertados deveriam se encaixar na categoria de mobiliário popular. A oferta pessoal de crédito dá condições do consumidor adquirir produtos à prazo, facilitando a compra. Segundo o Serasa Experian e Data Popular (2014), o crédito é responsável pelo crescimento exponencial da venda de móveis populares no Brasil.

A construção do protocolo de coleta de dados considerou as variáveis a serem verificadas, com base na literatura. Devido os dados serem verificados in loco, teve como técnicas principais: a observação direta, orientada por roteiro de observação e apoiada pela coleta de imagens. O roteiro de observação orientou a observação direta, buscando itens como as tipologias específicas de móveis com potencial para serem usados como divisórias entre ambientes nas habitações de interesse social, materiais, fixações, processos de montagem/desmontagem, necessidade de montador profissional, orientações gráficas aplicadas ao produto e externas a este, como manual de montagem. Além disto, à existência ou não, de dispositivos à prova de erros que pudessem auxiliar a montagem/desmontagem ou limpeza e segurança do produto.

Para coleta de informações não passíveis de observação direta (ex.: inclusão do custo de serviço de montagem especializada no preço final do produto), construiu-se um questionário, orientado aos representantes das lojas (vendedores, gerentes), para obter informações sobre a postura institucional em relação à montagem, nas residências dos consumidores, dos móveis vendidos pela loja. Para o Levantamento de 
Imagens, utilizou-se máquinas fotográficas e filmadoras. Os resultados da coleta de dados MS1 são apresentado a seguir.

\subsubsection{Resultados da Mini-Survey em Loja de Móveis Populares (MS1)}

Para a coleta de dados, priorizou-se a observação daqueles móveis que podem ser utilizados como divisória de ambientes, alinhando com os objetivo do Projeto Kits, como guarda-roupas, estantes e balcões. No total, foram avaliados 55 (cinquenta e cinco) produtos, sendo 25 guarda-roupas, 15 (quinze) estantes e 15 (quinze) balcões. Salienta-se que em $90 \%$ da amostra não foi permitida a coleta de imagens (fotografias/filmagens).

Isso posto, iniciou-se a coleta de dados observando as matérias-primas, que no roteiro de observação da MS1 estavam divididas entre ' base madeireira' e 'outros materiais'. Para a tipologia de móveis investigados, $96,36 \%$ do total de produtos avaliados, eram de base madeireira. Entre as madeiras reconstituídas, o MDF (Medium Density Fiberboard) estava presente em $88 \%$ dos guarda-roupas, em $80 \%$ das estantes e em $73,33 \%$ dos balcões. O HardBoard foi encontrado em $96 \%$ dos fundos de guardaroupas e suas gavetas e em $100 \%$ dos fundos das outras tipologias. 0 aglomerado foi encontrado na amostra de estantes, na proporção de $20 \%$ e na de balcões em $26,66 \%$. Das madeiras maciças, O Pinus aparece $4 \%$ da amostra de guarda-roupas.

Dos outros materiais, destacam-se os plásticos e metais, presentes $100 \%$ da amostra, em pequenas quantidades e divididos entre ferragens, detalhes e acabamentos. Outro material importante é o vidro, presente em $80 \%$ da amostra de estantes e em 53,33\% dos balcões, tanto em portas, como em prateleiras. Não foram encontrados outros materiais, como fibras, pedras e tecidos. Os acabamentos, no roteiro de observação estavam divididos em: madeira natural, lâminas de madeira, fórmica, papel melamínico, laca, pintura, verniz, cera e outros. O papel melamínico foi observado em $80 \%$ dos guarda-roupas, $66,66 \%$ das estantes e $60 \%$ dos balcões. 0 verniz figurava em $20 \%$ das estantes e balcões e em $4 \%$ dos guarda-roupas. Já a laca, era o acabamento de $16 \%$ dos guarda-roupas, não sendo encontrada nas outras tipologias. As lâminas de madeira natural apareceram em $20 \%$ dos balcões e 13,33\% das estantes, não sendo encontrada em guarda-roupas.

Quantos aos tipos de sistemas fixação ou união, estes estavam dividos no roteiro de observação em removíveis, semi-removíveis e permanentes, exemplificados respectivamente por 'encaixes', 'buchas e insertos', 'prego, grampo e cola'. Desta forma, junções tipo encaixe estavam presentes em $76 \%$ dos guarda-roupas e as cavilhas em $48 \%$ destes. Já as buchas, parafusos, ferragens e cola em $100 \%$ da amostra desta tipologia. O grampo é utilizado em $64 \%$ dos guarda-roupas e prego em $48 \%$. Entre as estantes, em $80 \%$ dos produtos analisados, encontraram-se encaixes, em $53,33 \%$ cavilhas e em $100 \%$, buchas e parafusos e cola. Em $13,33 \%$ das peças foi constatada a utilização de grampo e em $86,66 \%$ a presença de pregos. Nos balcões $80 \%$ apresentam fixação por encaixe e $46,66 \%$ fixação por cavilha. Ainda observou-se que, $53,33 \%$ utilizam cola, 33,33\% utilizam grampos e $66,66 \%$ usam pregos para a junção das partes. Em $100 \%$ da amostra foram observados os uso de buchas, parafusos e ferragens.

Além dos materiais apresentados, a observação direta envolveu também a busca por elementos visuais de apoio ao processo de montagem, seja com foco no montador, seja com foco no usuário final (orientações, alertas, instrução de 
montagem). Também buscou-se a existência de poka-yokes (dispositivos à prova de erros) integrados ao mobiliário, que auxiliassem no processo de montagem e desmontagem, evitando erros e colaborando para integridade física do móvel. Dados sobre a existência e oferta de profissionais de montagem foi, por sua vez, foram obtido pelo questionário. Isso posto, tem-se que: nenhum dos produtos observados continham Poka-Yokes, adesivos, orientações de uso/limpeza. Foi observado apenas um manual de montagem do produto, apresentado no Figura 1 a seguir.

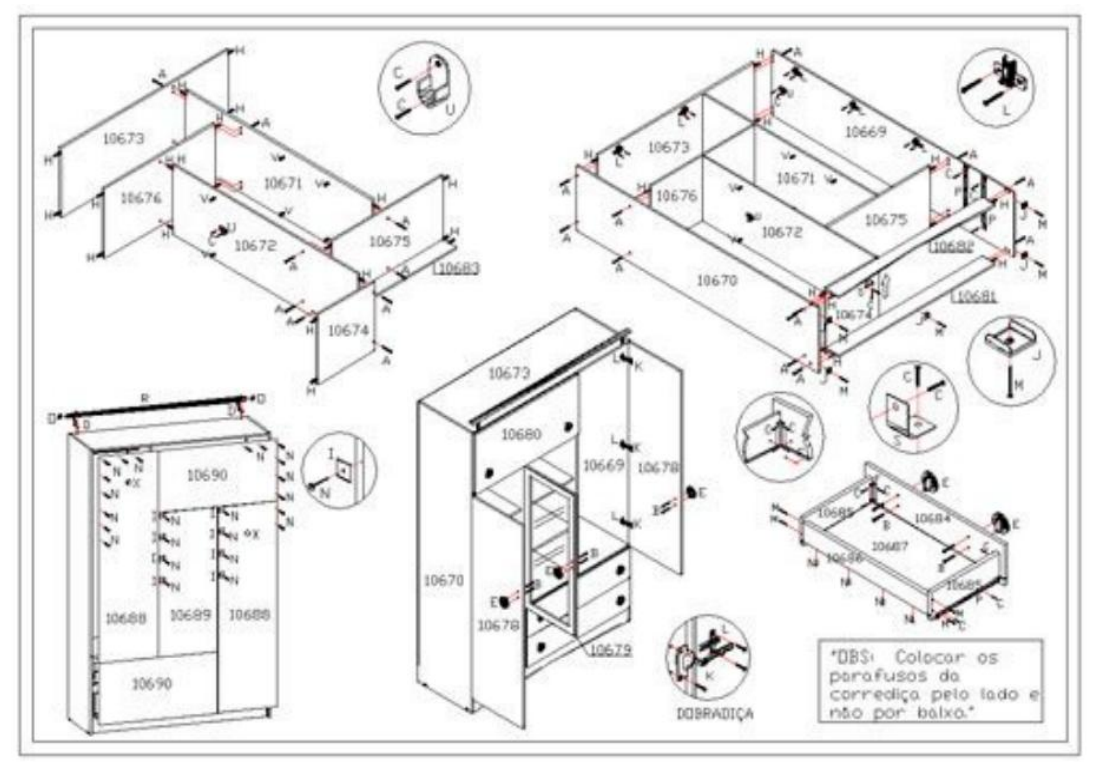

Figura 1 - Manual de Montagem do Produto Guarda-Roupa

Fonte: Elaborado pelo autor, com base na pesquisa realizada.

A Figura 1 traz um exemplo dos manuais de montagem que são entregues ao consumidor no ato da compra do produto. Contudo, através da aplicação do questionário aos responsáveis pela conclusão das vendas, obteve-se que $100 \%$ das lojas da amostra, tem como política oferecer 'entrega e montador profissional' para o produto, isentando-se de problemas resultantes de processos de montagem errôneas efetuadas pelo próprio usuário. Da mesma forma, 100\% das lojas se isentam de fixar os móveis nas paredes da casa dos clientes, alegando desconhecimento do projeto de elétrico/hidráulico da moradia.

Das reclamações advindas da entrega e montagem dos produtos, 30\% correspondem aos danos à superfície durante este processo e $70 \%$ relativas ao não cumprimento dos prazos de entrega. A análise dos dados apresentados nesta sessão é feita juntamente com a análise dos dados na Mini-Survey 2- MS2, cuja caracterização da amostra e os resultados são apresentados em sequência.

\subsection{Mini-Survey em Habitações Populares (MS2) - protocolo de coleta de dados}

Conforme citado, para confrontar os resultados obtidos Mini-Survey em Lojas de Móveis Populares (MS1), foi realizada uma segunda Mini-Survey, desta vez em Habitações de Interesse Social (MS2) com a intenção de coletar dados sobre o mobiliário em seu momento de uso. O principal critério de seleção das moradias foi a renda familiar de até três salários mínimos mensais (IPEA, 2013). Outro critério foi o tamanho da habitação, que não deveria ultrapassar $50 \mathrm{~m}^{2}$. Considerou-se também a 
variabilidade de estruturas familiares, buscando contemplar arranjos e necessidades diversas do ambiente construído.

O Protocolo de Coleta de Dados contou com: entrevista semi-estruturada, observação direta, roteiro de observação, coleta de imagem e som. O principal objetivo desta fase da pesquisa foi avaliar o período de uso do ciclo de vida do móvel popular, bem como os problemas que ocorrem fase e que podem encurtar a vida útil destes produtos. Isto incluiu analisar os erros humanos e violações nos processos de montagem e desmontagem, bem como fatores do contexto de uso que os induziram.

A entrevista semi-estruturada obteve dados gerais da família: formação, rendimento mensal, graus de escolaridade e questões pertinentes ao mobiliário: procedência, tempo de uso, usabilidade, possíveis montagens e desmontagens, erros, reestruturações, danos físicos e suas causas. Para dados sobre o estado físico do mobiliário, danos aparentes, aspectos técnicos, estéticos e funcionais, utilizou-se a observação direta, guiada por roteiro de observação. Para corroborar as anotações e permitir a validação interna das observações diretas, utilizou-se registro de imagens (fotografia e filmagem) e registro de áudio. Ambas as técnicas, sugeridas por Preece et al (2004) permitem a recuperação de dados visuais e de falas importantes à pesquisa e, portanto, a revisão do próprio conteúdo da análise.

\subsubsection{Resultados da Mini-Survey em Habitações Populares (MS2)}

A Mini-survey 2 procurou caracterizar o mobiliário em seu contexto uso. Para isto, foi selecionada uma amostra composta por 10 (dez) casas do Loteamento Sambaqui - Habitações de Interesse Social, na periferia da Cidade de Curitiba. O processo de seleção foi feito junto aos líderes da comunidade, com o intermédio de assistentes socias da COHAB/PR, que coordena a ocupação do local, seguindo os critérios já colocados. Assim, com a aplicação da entrevista semi-estruturada coletouse dados sobre: o respondente (titular), composição familiar, renda, escolaridade e residência, promovendo a caracterização das famílias da amostra.

Obteve-se que as dez famílias selecionadas para o estudo apresentaram um rendimento familiar médio de dois 'salários mínimos' mensais, com gasto superando o rendimento. Dos entrevistados, $80 \%$ possuíam fonte de renda no momento da pesquisa, tanto informal como formal. Quanto ao nível de escolaridade, $17,8 \%$ são analfabetos e $63,4 \%$ dos moradores ainda não completaram o ensino fundamental (COHAB, 2006). Todos os respondentes eram os proprietários titulares da residência no momento da pesquisa e o adensamento familiar variava entre 01(hum) e 05(cinco) moradores em $36 \mathrm{~m}^{2}$ de espaço construído.

Isso posto, a continuidade da entrevista semi-estruturada, juntamente com a observação direta, possibilitou coletar dados sobre o histórico do mobiliário da casa: origem, tempo com a família e desmontagens sofridas. Como resultado, tem-se que todos os móveis da amostra pertenciam à categoria de móveis residenciais, não sendo observado nenhum móvel de escritório. Entre as tipologias tipologias de mobiliário observaram-se: cama, guarda-roupa, armário, cômoda, balcão, assentos e estante.

Visto que o objetivo deste estudo é contrapor as ofertas do mercado com a realidade de uso do móvel, restringe-se a apresentar os dados referentes às tipologias compatíveis com as avaliadas na MS1 e, neste sentido, nenhum dos móveis estava sendo empregado com a função de separar ambientes. 
Para atender a função de guardar suas roupas, os moradores utilizavam guardaroupas, armários, gaveteiros e cômodas. Entre os guarda-roupas, 56,25\% tinham duas portas, $37,5 \%$ tinham seis portas e $6,25 \%$ tinham quatro portas. Observaram-se também, roupas empilhadas ou penduradas em pregos e cadeiras. Os sapatos eram guardados dentro dos guarda-roupas e armários e em sapateiras plásticas. Estante ou racks eram utilizados para apoio de aparelho de som e televisão em $30 \%$ das casas possuía, os demais utilizavam mesas, cadeiras ou piso para suprir suas funções. Verificou-se a utilização de armários do tipo balcão, balcão de pia, paneleiro vertical, armários superiores e prateleiras abertas, como solução para guardar utensílios e mantimentos.

Constatou-se que as matérias-primas de base madeireira predominavam na confecção da estrutura de 75,38\% móveis analisados, mantendo a mesma proporção em partes funcionais. Os mais freqüentes eram o pínus, as chapas de aglomerado de baixa densidade, o compensado (presente em menor quantidade) e o MDF (Médium Density Board). Outros materiais, de base não madeireira, como aço, vidro e plástico foram observados nos $24,62 \%$ dos móveis, sendo o plástico presente em 3,07\% em partes estruturais (lateral, fundo e porta de sapateira). Metais foram encontrados em $100 \%$ da amostra, em junções e uniões. O vidro por sua vez foi observado somente em partes funcionais, como portas e espelhos.

Os sistemas de junções/uniões das partes eram do tipo misto: permanente+semi-removível+removível, representados na Figura 2 respectivamente pelas letra C, B e A. Das junções removíveis pode-se observar o emprego de encaixes, parafusos, cavilhas sem cola e ferragens. Das junções permanentes, observou-se a utilização de cola, grampo e prego. Foram observadas, também, o uso de uniões permanentes na tentativa de consertar peças quebradas ou em vias de rompimento.

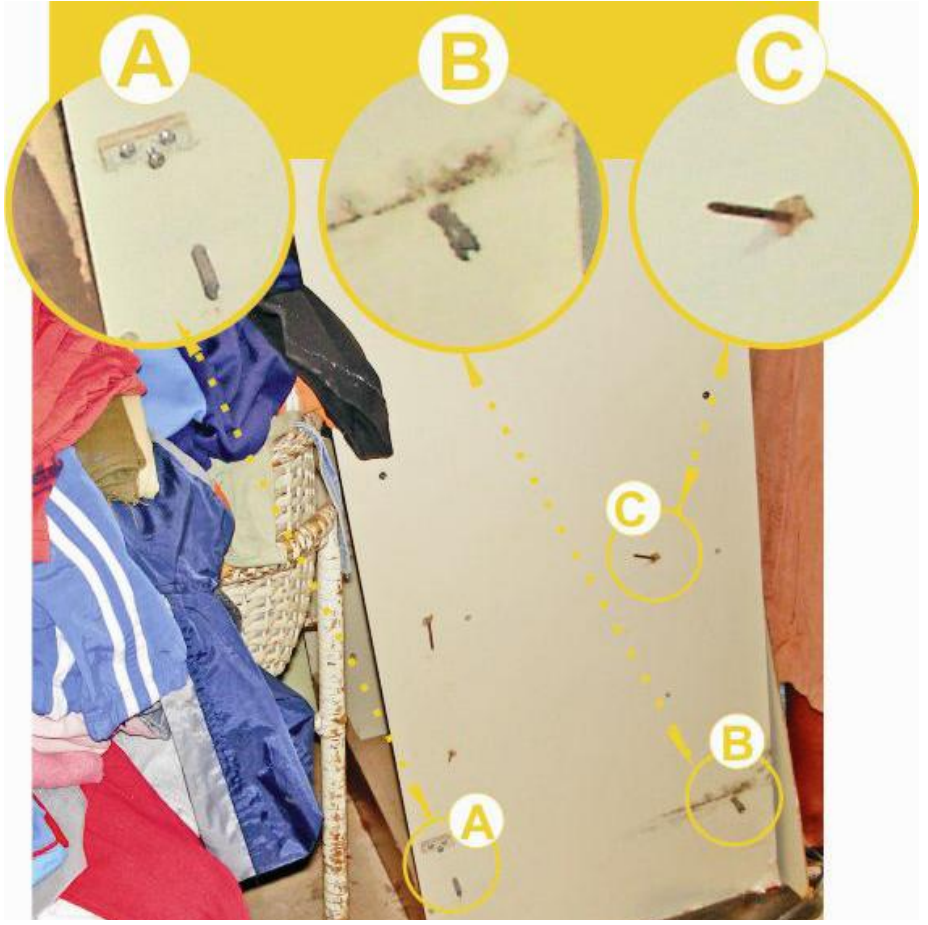

Figura 2 - Fixações Observadas em Móvel da Amostra MS2

Fonte: Elaborado pelo autor, com base na pesquisa realizada. 
Conforme mostra a Figura 2, fixações do tipo permanente, semi-permanente e removivel foram observadas contemporaneamente em móveis da amostra. Além destes, danos à superfície estavam presentes em 95,52\% dos móveis da amostra, nas formas leve ou severa. Como danos leves foram considerados aqueles que não comprometiam a estrutura do móvel, mas podiam comprometer a funcionalidade e a estética. Entre as forma leves encontravam-se riscos, furos, manchas, descascados e aplicação de adesivos.

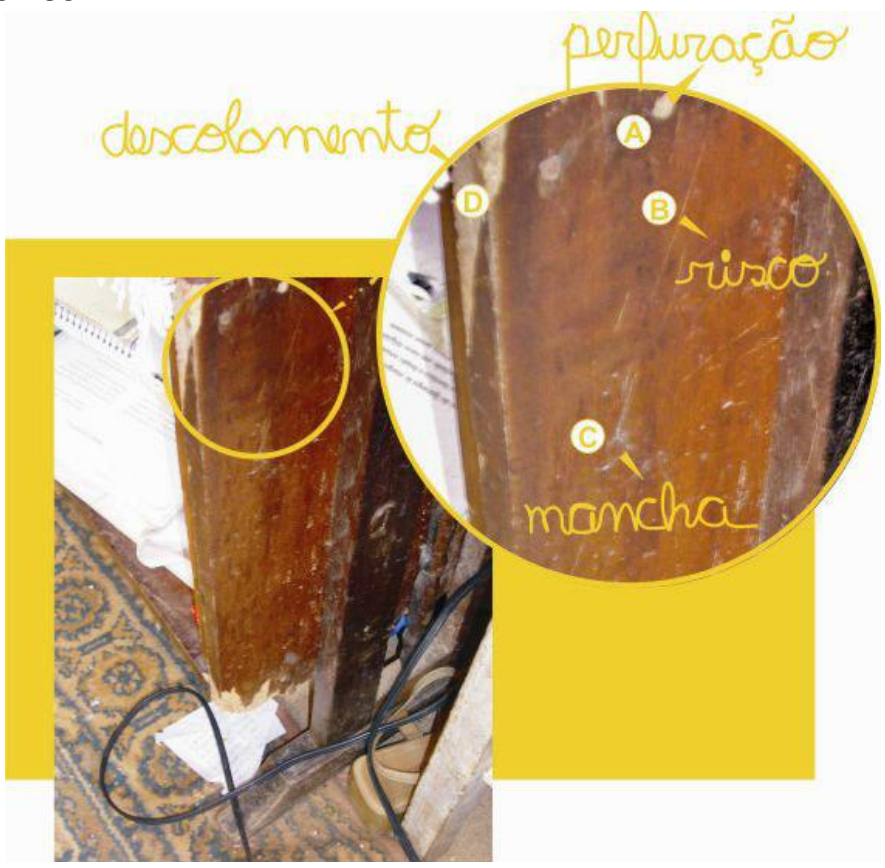

Figura 3 - Danos à Superfície de Móveis da Amostra MS2

Fonte: Elaborado pelo autor, com base na pesquisa realizada.

Conforme a Figura 3, foram vistos danos severos, principalmente com descolamentos de acabamentos com exposição do material interno, já apresentando processo de decomposição estrutural. Outros danos obsevados encontravam-se em ferragens e nas estruturas, compromentendo a segurança do usuário. Foram descritos acidentes graves decorrentes da forma ou desestruturação do móvel.

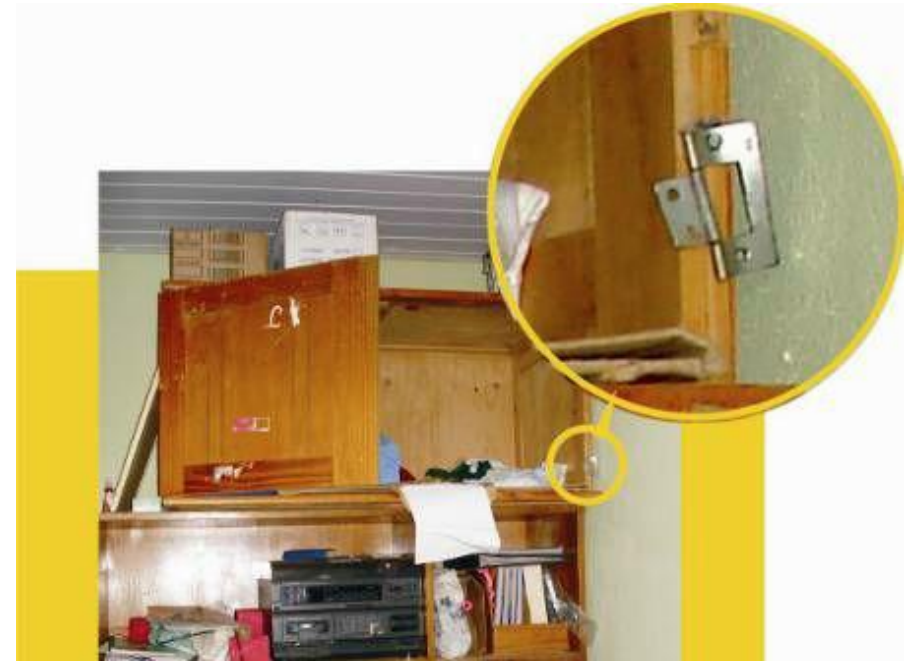

Figura 4 - Danos as Ferragens Observado em Móveis da Amostra MS2

Fonte: Elaborado pelo autor, com base na pesquisa realizada. 
A Figura 4 mostra danos as ferragens observados nos móveis da amostra, cujos dados sobre a procedência e o histórico de montagem/desmontagem foram coletados através da entrevista. Com ela obteve-se que $0,48 \%$ dos móveis foram comprados em loja de móveis novos e a montagem foi realizada por profissional. O referido produto, até o momento da pesquida, não havia sido desmontado. O comprador relatou, também, não ter recebido manual de montagem ou garantia da loja no momento da entrega. Dos demais produtos, $4 \%$ dos móveis foram feitos pelos próprios moradores, $60,15 \%$ era proveniente de doações (móveis usados por terceiros); 20,23\% eram móveis da família (remanescentes do processo migratório); 10,12\% eram móveis usados (encontrados após descarte); 5.02\% dos móveis era resultado de trocas por outros em lojas de móveis usados. Todos, sempre que possível, foram trazidos montados.

Apenas grandes estruturas, como guarda-roupas por exemplo, sofriam desmontagem parcial, sendo relatados problemas na remontagem, como perda das partes/componentes e falta de conhecimento/habilidade do morador. A montagem foi considerada um processo demorado, difícil, físico e mentalmente cansativo para $90 \%$ dos entrevistados. Somente $10 \%$ relataram habilidade na execução destes processos. Os mesmos $10 \%$ relataram também 'projetar e construir' móveis para suprir pequenas necessidades. O Entrevistado 1 relatou 'medo' de executar a montagem de um guardaroupa que estava há 20 (vinte) dias desmontado na sala de sua casa: "eu tenho medo de montar, (...) tentei montar só uma coisa na vida, a bicicleta do meu filho e não consegui." Outros $60 \%$ apontaram a dificuldade de visualizar o aspecto final do móvel após a montagem, conforme retrata a fala do Entrevistado 1: “(...) quando o móvel vem desmontado, a gente nem sabe como é que ele é, eu nem arrisco!".

Nenhum dos móveis doados foi entregue com manual ou instrução de montagem, assim como nenhum dos móveis de família possuía manual de montagem ou garantia do produto. Sobre a leitura de manuais de instrução ou instruções de uso ou montagem, $40 \%$ dos entrevistados responderam que lêem, referindo-se principalmente a celulares e bulas de remédios. Outros $60 \%$ responderam que não têm 'paciência' para ler nada. Não foram encontrados dispositivos à prova de erros integrados aos móveis que pudessem evitar lapsos ou impedir violações relacionadas à montagem/desmontagem do móvel ou à manutenção de sua integridade física. As conseqüências desta realidade serão discutidas na análise a seguir.

\subsection{Análise das Mini-Survey 1 e Mini-Survey 2}

Os dados apresentados na MS1 mostraram que os móveis são fabricados pelas indústrias empregando grande heterogeneidade de materiais. Esta condição exige soluções de design que facilitem a separação dos materiais ao final do ciclo de vida, o que não foi observado. Os móveis da amostra utilizavam sistemas mistos, incluindo junções permanentes que dificultam a separação das partes e componentes para reciclagem e/ou recuperação energética. Ainda sobre os sistemas de fixação dá-se na análise de que, durante a fase de uso do ciclo de vida do móvel, poderem ocorrer desgaste ou ruptura de algum componente, que necessite de reparo ou reposição e esta poderia ser impedida por sistemas de fixação do tipo permanente. Além de dificultar manutenções preventivas e corretivas, este tipo de junção inibe a adaptabilidade estrutural, funcional e estética do mobiliário durante sua fase de uso, 
estratégias que poderiam garantir a durabilidade do produto, conforme apontam Manzini e Vezzoli (2005).

Em relação à questão estética, observou-se outra incongruência entre oferta/uso desta categoria de mobiliário. Segundo a MS1, existe predominância do papel melamínico na oferta, cuja durabilidade frente aos demais acabamentos é bastante reduzida, sendo mais propenso a riscos e descolamentos de superfície. Danos à superfície, como riscos, manchas e emprego de adesivos (danos leves) e descolamento com exposição da estrutura (danos graves), foram observados na MS2. Além disto, cada tipo de superfície requer cuidados específicos para sua manutenção, geralmente apresentados por indicações de design informacional. Porém, na MS1, em nenhum produto foram observadas estas considerações, o que poderia aumentar as possibilidades de danos à superfície durante o uso do produto. Pode-se considerar reflexo disto, manchas observadas na MS2, relatadas como resultado da utilização de produto químico de limpeza. Acabamentos também podem sofrer danos no transporte, montagem e desmontagem, mesmo quando realizados por profissionais, como mostrou a MS1. Isto poderia explicar a posição das lojas, tanto de oferecer o serviço de um montador profissional no ato da compra do produto, como de se isentar de responsabilidades sobre os danos causados ao móvel durante a montagem.

Contudo, segundo a MS2, os móveis encontrados nas residências pesquisadas são, em sua maioria provenientes de doações, cujo contexto de uso nas residências anteriores, número de donos, processos montagem/desmontagem e transporte não foi possível precisar. Doações não incluem serviço de montador profissional, cujo custo inibe a contratação por famílias de baixo poder financeiro. Os dados mostram que o mobiliário popular, durante a sua vida útil, sofre realmente grande quantidade de desmontagens e re-montagens, fato a ser considerado pelo Design, facilitando a interface com os sistemas de junção, tornando o processo intuitivo e alertando para existência de erros que possam prejudicar o móvel. $O$ design informacional que deveria instruir os processos, é de difícil compreensão para leigos. Isto, somado ao número de componentes e uso de sistemas mistos de junção, resulta em um produto de montagem complexa para pessoas inexperientes.

Assim, de um lado, têm-se um público inapto para a tarefa: com pouca ou nenhuma familiaridade com este tipo de atividade, inseguro cognitiva e emocionalmente, desprovido de ferramentas adequadas e, contudo, disposto a executar a atividade em prol do bem-estar da família na moradia. De outro lado, têmse móveis não projetados para serem desmontados e menos ainda para ser 'constantemente desmontados e remontados', como exige a realidade desta população. Móveis cujos materiais, componentes e acabamentos não comportam a longevidade necessária para atender as demandas do público ao qual é ofertado. Tudo isto, ainda é agravado pelo ambiente no qual se dá a interface: a própria moradia popular, com espaços exíguos, número excesivo de moradores, por vezes baixa luminosidade e nivelamento do terreno nem sempre adequado para a execução de montagens e desmontagem de móveis conforme resume a Figura 5 a seguir: 


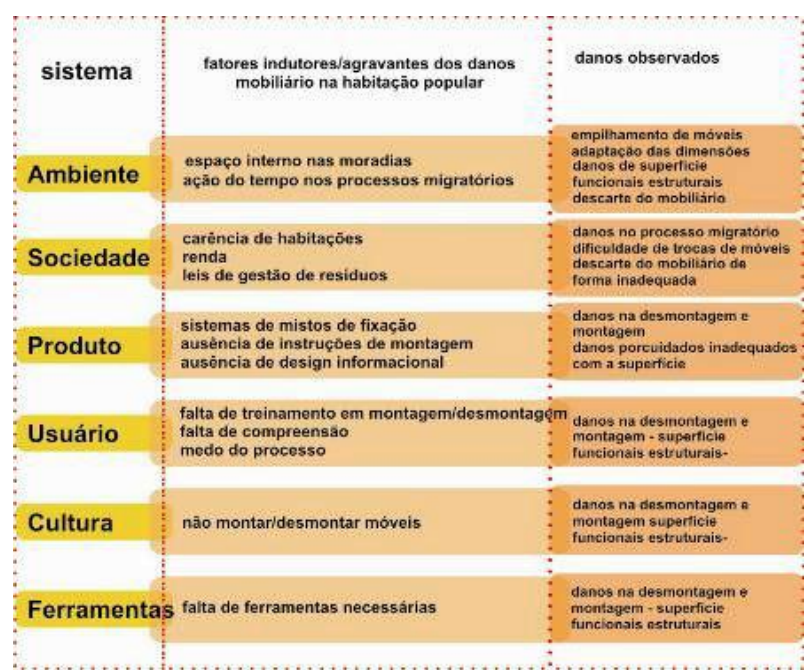

Figura 5 - Fatores que atuam na atividade de montar/desmontar móveis populares.

Fonte: Elaborado pelo autor, com base na pesquisa realizada.

A Figura 5 sintetiza os fatores que atuam no processo de montar/desmontar móveis populares, executados pelas famílias de baixa renda, em suas moradias de interesse social. Neste quadro destaca-se as deficiências do produtos em relação ao usuário e o sistema no qual vive e os danos resultados desta interface inadequada.

Cabe ao designer compreender as reais demandas do usuário e adequar o produto a elas. Portanto, todos os dados levam a conclusão que o emprego de pokayokes para facilitar a desmontagem/montagem, nestes produtos, poderia ser uma solução viável para grande parte dos problemas apresentados acima.

\section{CONCLUSÃO}

Durante o desenvolvimento desta pesquisa pôde-se verificar a incoerência e as incongruências existentes entre o design de móveis populares ofertados pelo mercado e as demandas da população de baixa renda em moradias de interesse social. Verificou-se também, que as classes $C, D, E$, através das ofertas de crédito pelas lojas de produtos populares, têm cada vez mais acesso ao consumo de bens duráveis e precisam de soluções em design de mobiliário que atendam as suas necessidades de mobilidade, flexibilidade e adaptabilidade e que contemplem as mudanças que ocorrem durante o ciclo de vida da família.

Com isto, esta pesquisa sugere melhorias para design de móveis populares entre as quais: a redução da diversidade de materiais no produto, escolha de matérias primas com maior durabilidade, uso de acabamentos de alta resistência físico/quimico/mecânica, emprego de sistema de encaixe no lugar de fixação, utilização de sistemas removíveis, design de interface de montagem e desmontagem intuitivas e design informacional simplificado voltado ao usuário final.

A pesquisa sugere também que o design para a montagem/desmontagem de móveis populares pode benificiar-se com a intergração de dispositivos Poka-Yoke ao sistema, facilitando o desmembramento de partes, assegurando a integridade física do produto, evitando seu descarte prematuro e todos os inputs e outputs por ele gerados. Seu emprego pode atender contemporaneamente os requisitos da indústria, com relação ao baixo custo de implementação das soluções, e do usuário, com relações às suas necessidades. Portanto, a utilização de poka-yoke é uma estratégia a ser considerada no design de móveis populares, sendo uma contribuição efetiva para a 
sustentabilidade, para a melhoria das condições de vida da população de baixa renda, para sua interface com ambiente construído da Habitação de Interesse Social e usufruto adequado do espaço físico denominado Lar.

\section{AGRADECIMENTOS}

Esta pesquisa deve-se ao Núcleo de Design e Sustentabilidade da UFPR, ao Prof. Dr. Aguinaldo dos Santos e aos professores e colegas do PPGDesign-UFPR, à FINEP, à CAPES, ao CNPq, à MASISA, à COHAB-CTBA e ao moradores do Conjunto Habitacional Moradias Sambaqui. À todos os sinceros agradecimentos.

\section{REFERÊNCIAS}

BERNARDES, Júlio. Indústria Moveleira Direcionada ao Mercado Popular tem Melhor Desempenho Financeiro. São Paulo: Agência USP de Notícias, 2014. Disponível na internet por http em: <www5.usp.br/40485/industria-moveleira-direcionada-ao mercado-popular-tem-melhor-desempenho-financeiro/>. Acesso em 18 abril 2014.

COHAB-CT. Apresentação de Estudo - Moradias Sambaqui. 2007

DATA POPULAR. Faces da Classe Média. Disponível por http em: www.serasaexperian.com.br.> Acesso em abril 2014.

FREITAS, Henrique et. al. O Método de Pesquisa Survey. Revista de Administração V.35, n.3, p.105-112: São Paulo, julho/setembro, 2000.

IPEA. Disponível na internet por http em: $<$ http://www.ipea.gov.br/portal/index.php?option=com_content\&view=article\&id=20 656

LEPRE, Priscilla Ramalho. Diretrizes para Aplicação de Dispositivos Poka-Yoke no Design de Mobiliário: uma estratégia para o design sustentável. 2008. $226 \mathrm{f}$. Dissertação - Universidade Federal do Paraná, Programa de Pós-Graduação em Design.

MANZINI, Ezio; Vezzoli, Carlo. O Desenvolvimento de Produtos Sustentáveis: Os Requisitos Ambientais dos Produtos Industriais. São Paulo: EDUSP, 2005.

PASSOS, Carlos Augusto. A Eficiência e a Estratégia das Empresas que Atuam no Mercado de Móveis Populares no Brasil: um estudo sobre o setor de móveis. 2013. 166 f. Dissertação - Universidade de São Paulo, Programa de Pós-Graduação em Administração.

PREECE, Jenny et. al. Interaction Design. Milano : Apogeo Editore, 2004.

ROBSON, Colin. Real Word Research. Padstow: Blackwell Publishing, 2006.

SOARES, Melri A. T.; NASCIMENTO, Marilzete B. do. Moradia e Mobiliário Popular: problema antigo solução (im)possível? Da Vinci, v.5 n.1, p.69-69: Curitiba, 2008. 